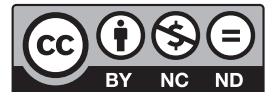

Estudos Teológicos foi licenciado com uma Licença Creative Commons Atribuição - NãoComercial - SemDerivados 3.0 Não Adaptada

http://dx.doi.org/10.22351/et.v58i2.3286

\title{
TEOLOGIA DO RECONHECIMENTO: PROVOCAÇões deCOLONIAIS E A ÉTICA do BEM COMUM ${ }^{1}$
}

\author{
Theology of recognition: \\ decolonial provocations and Ethics of the Common Good
}

Carlos Alberto Motta Cunha ${ }^{2}$

Resumo: Nosso objetivo é propor uma intelecção da fé em perspectiva decolonial, que aqui chamamos de "teologia do reconhecimento". Ou seja, repensar não só a epistemologia da teologia, mas também sua tarefa, iluminadas pela situação de colonização dos excluídos. Esse húmus de reflexão também permite avaliar criticamente os interesses por trás de uma teologia hegemônica propiciando, como sugere Juan Luis Segundo, a libertação da própria teologia. Para isso, faremos uma breve introdução sobre a situação de intolerância, tolerância e reconhecimento na atualidade, para, no segundo momento, avaliar criticamente as provocações decolonias à teologia e, por fim, propor uma intelecção da fé disposta a "ouvir" o grito dos excluídos e com eles refazer a tarefa teológica a luz da ética do Bem Comum. O caminho proposto permite uma formação teológica em diálogo com as teorias decoloniais e capaz de abraçar horizontes mais amplos, reconhecendo as minorias e sua importância não só para a teologia, mas para a construção de outro mundo possível.

Palavras-chave: Teologia cristã. Reconhecimento. Pensamento decolonial. Ética. Bem Comum.

\begin{abstract}
This paper aims to propose an intellection of faith in a decolonial perspective, which we call here "theology of recognition". Namely, the need to rethink the epistemology of theology as well as its task, in the light of the colonization of the excluded. This core of reflection also allows for a critical evaluation of the interests behind a hegemonic theology providing, as suggested by Juan Luis Segundo, the liberation of theology. In order to do so, we will briefly introduce the present situation of intolerance, tolerance and recognition, before evaluating critically the decolonial provocations directed at theology. Finally, we will propose an intellection of faith, willing to "hear" the cry of the excluded and, with them, reshape the theological task in the light of the ethics of the Common Good. This path promotes a theological
\end{abstract}

1 O artigo foi recebido em 02 de abril de 2018 e aprovado em 05 de outubro de 2018 com base nas avaliações dos pareceristas ad hoc.

2 Doutor em Teologia, bolsista do PNPD-CAPES e professor colaborador no PPG em Teologia da Faculdade Jesuíta de Filosofia e Teologia em Belo Horizonte/MG. Contato: carlosamc04@gmail.com 
formation dialoguing with decolonial theories and able to embrace broader horizons by recognizing minorities and their importance not only for theology, but also for the construction of another possible world.

Keywords: Christian Theology. Recognition. Decolonial Thought. Ethics. Common Good.

\section{Introdução}

A teologia do reconhecimento não é uma nova teologia do genitivo. O termo "reconhecimento", utilizado aqui e atrelado à teologia, evoca uma tarefa desafiadora para uma intelecção da fé que almeja contestar sistemas totalitários e seus mecanismos de exclusão. Uma teologia em perspectiva decolonial é marcada não só pela desobediência epistêmica de referenciais teóricos incapazes de reconhecer a legitimidade do labor teológico feito nas periferias, mas, sobretudo, impulsionada por práticas libertadoras concretas. Para reforçar esse "fazer decolonial" da teologia, propomos um diálogo provocador entre a teologia cristã e o pensamento decolonial com o objetivo de repensar a tarefa teológica a partir do reconhecimento dos excluídos e balizada pela ética do Bem Comum.

O "uni-verso" (unidade a partir do diverso) daqueles que foram excluídos e marginalizados desafia a teologia de hoje a rever seus conceitos e sua práxis diante de uma realidade marcada pelo sofrimento de pessoas que foram silenciadas pelo poder hegemônico. O sistema colonial negou a esses seres humanos, e às suas respectivas culturas, o privilégio da manifestação ao mundo da sua riqueza identitária. Graças aos movimentos pós-coloniais e decoloniais, dos grupos de estudos subalternos do Sul Global, passando pelas reflexões do grupo modernidade/colonialidade, a voz do subalternizado pode ser ouvida na atualidade e garantido o seu direito à vida.

Para um fazer teológico libertador, que almeja ser público e pertinente, é impossível ignorar ou colocar-se à margem das profundas transformações culturais do nosso tempo. Novas interpelações impõem-se à teologia obrigando-a a um alargamento do seu conceito e de sua tarefa. Acreditamos que o pensamento decolonial é uma chave de leitura importante para potencializar a perspectiva libertadora de teologias progressistas do Sul Global. Essas teologias abraçam dentro de si um leque de possibilidades e novidades para uma intelecção da fé efetivamente decolonial.

No início de 1970, Juan Luis Segundo já falava sobre a libertação da teologia das amarras colonizadoras no seu livro Libertação da Teologia. Essa libertação acontece quando a teologia se submete ao exercício libertador de suas ideias e métodos arcaicos próprios de um labor teológico encerrado em sua torre de marfim. Remexer a base da teologia cristã a partir das demandas dos excluídos e exigir que ela tenha uma palavra/ação efetiva parece ser fundamental para uma teologia que anseia ser contextual. ${ }^{3}$

3 SEGUNDO, Juan Luis. Libertação da teologia. São Paulo: Loyola, 1978. p. 252. 
Assim, o caminho proposto no nosso artigo consiste em mostrar que, em um mundo marcado por tanta intolerância, o reconhecimento do outro, mais do que a tolerância, abre espaço para a aceitação e o respeito pelos "diferentes". No segundo momento, avaliamos criticamente as provocações decolonias à teologia e, por fim, fazemos apontamentos para uma teologia disposta a "ouvir" o grito dos excluídos e com eles refazer a sua tarefa à luz da ética do Bem Comum. Nossa caminhada permite pensar na possibilidade de uma formação teológica capaz de abraçar horizontes mais amplos, reconhecendo as minorias e sua importância não só para a inteligência da fé, mas para a construção de outro mundo possível.

\section{Intolerância, tolerância e reconhecimento}

O sistema moderno/colonial favorece a intolerância. Historicamente, com o processo de racialização, classificação e hierarquização, a intransigência em relação ao diferente tem sido uma constante. ${ }^{4}$ A coação e a força têm sido os instrumentos para a repressão de opiniões, comportamentos, crenças e modos de ser tidos como errados pelos intolerantes. O mundo cada vez mais globalizado e conectado compartilha atos de intolerância por toda parte. Os motivos para tal são os mais variados possíveis. Desde guerras entre países a conflitos de classes e religiosos, o planeta tem sido palco das mais terríveis atitudes de intolerância extrema gerando dor, sofrimento e muita morte.

A intolerância não tem um espaço definido. Suas manifestações estão disseminadas por todos os lugares, independentes do status socioeconômico. Presenciamos atitudes de homofobia, xenofobia, racismo e intolerância religiosa (só para ficar nas mais comuns) todos os dias. Para a antropóloga francesa Françoise Héritier, a intolerância manifesta-se na dificuldade de reconhecer a expressão da condição humana na figura de tudo o que nos é absolutamente diverso. Sob tal perspectiva, a intolerância consiste em restringir a definição de humano ao "diferente", sendo não humano. Já para Leonardo Boff, a intolerância

Reduz a realidade, pois assume apenas um polo e nega o outro. Coage a todos a assumir o seu polo e a anula o outro, como o faz de forma criminosa o Estado Islâmico e a Al Qaeda. O fundamentalismo e o dogmatismo tornam absoluta a sua verdade. Assim eles se condenam à intolerância e passam a não reconhecer e a respeitar a verdade do

4 Para Aníbal Quijano, a questão da classificação social é um instrumento importante para a empresa colonial. Raça, gênero e trabalho foram as três linhas principais de classificação que constituíram a formação de um sistema mundial colonial/moderno no século XVI. É nessas três instâncias que as relações de exploração/ dominação/conflito estão ordenadas. Cf. QUIJANO, Aníbal. Colonialidad del poder y clasificación social. p. 285. Disponível em: <http://biblioteca.clacso.edu.ar/clacso/se/20140506032333/eje1-7.pdf>. Acesso em: 06 fev. 2018.

5 HÉRITIER, Françoise. O eu, o outro e a intolerância. In: BARRET-DUCROCQ (dir.). A intolerância: Foro Internacional sobre a Intolerância, Unesco, 27 de março de 1997, La Sorbonne, 28 de março de 1997. Rio de Janeiro: Bertrand Brasil, 2000. p. 25. 
outro. O primeiro que fazem é suprimir a liberdade de opinião, o pluralismo e impor o pensamento único ${ }^{6}$.

Seria a tolerância então uma resposta ideal para a intolerância? Sim e não, isto é, a tolerância não seria uma boa resposta para a intransigência quando ela se limita a uma tendência a admitir, nos outros, modos de pensar e agir "diferentes". Aí ela seria, como diria Boaventura de Sousa Santos, uma resposta fraca a perguntas fortes da contemporaneidade. ${ }^{7}$ A tolerância é uma resposta forte quando, para além da tendência da aceitação, acolhe efetivamente as diferenças, quer dizer, quando provoca o reconhecimento. Segundo Héritier:

Se o Eu implica um Outro necessariamente diferente e, portanto, o estabelecimento de critérios de reconhecimento, a lógica da diferença não deveria acarretar, automaticamente, nem a hierarquia, nem a desconfiança, nem o ódio, nem a exploração, nem a violência. [...] Tolerar é, portanto, aceitar a ideia de que os homens não são definidos apenas como livres e iguais em direito, mas que todos os humanos sem exceção são definidos como homens. Sem dúvida, é aí que reside o fundamento de uma hipotética ética universal, com a condição - que comporta consideráveis condições - de que haja uma tomada de consciência individual e coletiva, uma vontade política internacional e o estabelecimento definitivo de sistemas educacionais que ensinem a não odiar ${ }^{8}$.

Não basta, na atualidade, ser tolerante no sentido de somente respeitar as diferenças. O reconhecimento, mais do que esse tipo de postura tolerante, surge como resposta forte às sociedades plurais de hoje. Reconhecer é dar sentido e legitimidade ao outro. É um ato libertador. Já o tolerar, por mais que se admitem modos de pensar, agir e de sentir diferentes das nossas, não é capaz de conferir ao diferente a dignidade que lhe é merecida.

Dentre os vários autores que escreveram de forma direta ou indireta sobre o tema do reconhecimento, selecionamos dois filósofos que viveram em épocas distintas e que, nos seus escritos, o tema do reconhecimento aparece de forma esclarecedora. Pinçar, com todo cuidado para evitar interpretações equivocadas, o tema do contexto das suas reflexões pode ajudar na elaboração de uma teologia do reconhecimento sensível à diversidade do tempo atual. Não faremos uma exposição sobre o pensamento desses autores, mas iremos direto ao modo como eles trabalham a ideia do reconhecimento em obras específicas. Para essa finalidade, uma breve introdução sobre a filosofia de cada um basta.

6 BOFF, Leonardo. A intolerância no Brasil atual e no mundo. Disponível em: <https://leonardoboff. wordpress.com/2015/01/22/a-intolerancia-no-brasil-atual-e-nomundo/>. Acesso em: 06 fev. 2018.

7 Boaventura de Sousa Santos diz: "O nosso tempo não é um tempo de respostas fortes. É antes um tempo de perguntas fortes e de respostas fracas". Cf. SANTOS, Boaventura de Sousa. Os direitos humanos na zona de contacto entre globalizações rivais. Disponível em: <http://www.boaventuradesousasantos.pt/ media/Direitos\%20humanos\%20globaliza\%C3\%A7\%C3\%B5es\%20rivais_Cronos2007.pdf>. Acesso em: 07 fev. 2018.

8 HÉRITIER, 2000, p. 27. 


\section{O reconhecimento na dialética do senhor e do escravo de Hegel}

O primeiro filósofo é Georg Wilhelm Friedrich Hegel (1770-1831). O mais importante filósofo do idealismo alemão pós-kantiano e um dos que mais influenciou o pensamento de sua época e o desenvolvimento posterior da filosofia. Situado entre o racionalismo de Kant, excessivamente formalista e voltado para o ideal do conhecimento, e a irracionalidade dos românticos, inspirados na intuição e nos sentimentos, a filosofia de Hegel pode ser considerada o último grande sistema da tradição clássica. O idealismo hegeliano é complexo. Sua elaboração filosófica está enraizada nos eventos históricos transcorridos durante sua vida, como a Revolução Francesa e as guerras napoleônicas.

A filosofia de Hegel parte da necessidade de examinar as etapas de formação da consciência, tanto em seu sentido subjetivo, no indivíduo, como em seu sentido histórico, ou cultural, representado pelo desenvolvimento do espírito (Geist). Sua obra clássica Fenomenologia do espírito (1807) inaugura esse pensamento. Para o filósofo alemão, a consciência é o resultado de um processo de formação, mas também de seu lugar na história. O percurso da consciência humana vai até o espírito absoluto, quer dizer, as etapas do caminho que o espírito percorre através da consciência humana até chegar em si mesmo. É o saber humano em busca da verdade e em sua direção ao Absoluto. ${ }^{9}$

No capítulo IV da Fenomenologia do espírito, Hegel aborda o tema da dialética ${ }^{10}$ do senhor e do escravo. $\mathrm{O}$ assunto também está presente em outros textos hegelianos. O senhor e o escravo são figuras filosóficas para entender o momento do reconhecimento de si e do outro. Para ter consciência de si precisa ter consciência do outro, aquele que se opõe. A consciência-de-si é em si e para si, porque necessita buscar sua verdade pelo reconhecimento de outra consciência-de-si. Assim acontece o desdobramento da unidade espiritual, denominada por Hegel como movimento de reconhecimento. Consciência-de-si e consciência para outra são dois momentos representados por duas figuras opostas da consciência: a primeira, a consciência independente do senhor, cuja essência é o ser-para-si e, a segunda, a consciência dependente do escravo, cuja essência é a vida. Segundo Hegel:

Mediante essa experiência se põem uma pura consciência-de-si e uma consciência que não é puramente para si, mas para um outro [...] São essenciais ambos os momentos; porém como, de início, são desiguais e opostos, e ainda não resultou sua reflexão na unidade, assim os dois momentos são como duas figuras opostas da consciência: uma, a

9 Cf. A apresentação que o filósofo jesuíta Henrique Cláudio de Lima Vaz faz da obra clássica de Hegel. In: HEGEL, Georg Wilhelm Friedrich. Fenomenologia do espírito. 9. ed. Petrópolis: Vozes; Bragança Paulista: Ed. Universitária São Francisco, 2014. p. 11-22.

${ }^{10}$ Segundo Sponville, dialética é um "pensamento da complexidade, da interdependência, da não-separação. Para o dialético, tudo está em tudo e vice-versa". Citando o próprio Hegel, Sponville acrescenta: "O movimento racional superior no qual termos que parecem totalmente separados transformam-se um no outro por si mesmos, pelo próprio fato do que são, e no qual a pressuposição da sua separação se suprime" (Lógica, 1,1). Cf. COMTE-SPONVILLE, André. Dicionário filosófico. São Paulo: Martins Fontes, 2003. p. 163. 
consciência independente, para a qual o ser-para-si é a essência; a outra, a consciência dependente, para a qual a essência é a vida, ou o ser para um Outro. Uma é o senhor, outra é o escravo ${ }^{11}$.

A imagem proposta por Hegel sugere a importância da relação com o outro na constituição da identidade. Dentro da dialética do senhor e do escravo emerge o reconhecimento de cada um à medida que a relação entre eles aguça a consciência-de-si e do lugar que ocupa na hierarquia das posições que assumiu. $\mathrm{O}$ escravo é escravo porque tem um senhor que manda e a ele deve subordinação. Quanto ao senhor, ele não teria consciência-de-si sem a figura do escravo, isto é, ao exigir trabalho e submissão do escravo, o senhor percebe o quanto é dependente do escravo e o risco de não-ser caso o escravo se rebelasse. A partir de então, o senhor assume a posição de escravo. $\mathrm{O}$ escravo revela o mundo pobre do senhor porque este só tem o escravo enquanto aquele tem a força do trabalho. ${ }^{12}$

Henrique C. de Lima Vaz faz duas considerações importantes sobre a dialética do senhor e do escravo. Primeira:

Parábola filosófica ou evocação, na forma de uma história exemplar, do percurso dialético que vai da imediata adesão à vida do indivíduo submetido à pulsão do desejo, à liberdade do indivíduo que se universaliza pela reciprocidade do consenso racional: eis a significação da figura do Senhorio e da Servidão na estrutura da Fenomenologia ${ }^{13}$.

\section{Segunda:}

Para Hegel, Senhor e Escravo não são personagens de uma espécie de situação arquetipal da qual procederia a história. São apenas figuras de uma parábola com as quais Hegel pretende designar momentos dialéticos entrelaçados rigorosamente no discurso que expõe a formação do indivíduo para o saber. Esse saber deve apresentar-se como fundamento para a exigência histórica de uma sociedade do reconhecimento universal. Por sua vez, tal exigência está inscrita na própria história da cultura ocidental desde a sua aurora grega, quando fez do logos ou da filosofia o guia da sua alma, o seu paychagogós nos caminhos do tempo ${ }^{14}$.

Assim, entender o sentido do reconhecimento fora do campo hegeliano significa aderir à dialética como política de reconhecimento entre grupos. A consciência de um depende de passar pelo outro e voltar para si num processo constante de mutabilidade capaz de mudar o caráter dos personagens no decorrer da dialética. Exercício tão importante para a aceitação das diferenças e legitimação do outro. Eliminando o outro, eu empobreço a mim mesmo e o mundo. É o reconhecimento que dá a riqueza

\footnotetext{
11 HEGEL, 2014, p. 146-147.

12 HEGEL, 2014, p. 147-151.

13 VAZ, Henrique C. de Lima. Senhor e Escravo: uma parábola da filosofia ocidental, p. 23. Disponível em: $<$ faje.edu.br/periodicos/index.php/Sintese/article/download/2175/2468>. Acesso em: 08 fev. 2018.

14 VAZ, 2018, p. 23.
} 
da relação. Excluir o outro com posturas totalizantes é eliminar a si mesmo. Portanto é preciso ter cautela com quem desqualificamos, porque podemos desqualificar exatamente aquele que nos reconhece.

\section{O percurso do reconhecimento de Ricoeur}

O segundo filósofo que nos auxilia na compreensão do reconhecimento é Paul Ricoeur (1913-2005), filósofo francês do pós-guerra. Seu pensamento busca uma teoria da interpretação do ser; uma hermenêutica do sentido. Para ele, todo pensamento moderno tornou-se uma interpretação que, quando revisada, se apresenta como uma teoria das operações de compreensão em sua relação com a interpretação dos textos. O símbolo que emerge daí exprime a experiência fundamental do ser humano. Assim, o filósofo francês elabora uma filosofia da linguagem capaz de elucidar as múltiplas funções do significado humano. Porque o símbolo nos leva a pensar.

O pensamento ricoeuriano apresenta-se rico e criativo. Aberto ao diálogo com os "melhores adversários", Ricoeur elabora sua filosofia a partir de situações concretas e desafiantes. Cada livro dele preocupa-se com uma questão específica e, ao mesmo tempo, deixa um resíduo, uma questão aberta para novas elaborações filosóficas. Ricoeur mantém uma linha de evolução na compreensão de determinados temas de modo a desenvolvê-los com maior clareza e abrangência em publicações posteriores. É o caso da "identidade narrativa", que aparece nas últimas páginas do terceiro volume de Tempo e Narrativa (1985) desenvolvida em O si-mesmo como outro (1990). ${ }^{15}$

No livro Percurso do reconhecimento (2004), um dos últimos textos do nosso filósofo cristão, Ricoeur debruça-se sobre a necessidade da elaboração de uma filosofia do reconhecimento. Para isso ele identifica os vários significados da palavra reconhecimento nos dicionários "Littré" e "Grand Robert", visando constituir um itinerário (percurso) filosófico de passagem da compreensão do termo como: primeiro, noção epistemológica no modo de distinguir, no fluxo permanente das aparências, a permanência de uma identidade, seja ela a de uma substância, de uma forma ou de um conceito; segundo, enquanto capacidade antropológica de reconhecimento de si a partir da identificação das coisas. Nesse processo se inserem igualmente as práticas sociais e a constituição das identidades coletivas. O sujeito identifica-se à medida que é identificado por outros. E, terceiro, reconhecimento como noção política, isto é, o reconhecimento mútuo fruto da identidade reconhecida por um outro que quer o mesmo. Aqui Ricoeur intensifica o diálogo com o pensamento de Hegel, reatualizando-o e esclarecendo seus prolongamentos possíveis em nossa atualidade multicultural. ${ }^{16}$

Ao enumerar ao menos três sentidos de reconhecimento: "como identificação", "se reconhecer a si mesmo" e "o reconhecimento mútuo", ou como identidade, alte-

${ }^{15}$ Cf. A entrevista de Paul Ricoeur ao falar sobre a sua trajetória filosófica. Disponível em: <https://www. youtube.com/watch?v=OFwyp1689pQ>. Acesso em: 15 fev. 2018.

${ }^{16}$ Cf. A entrevista de Paul Ricoeur, falando sobre o livro Percurso do reconhecimento, feita por Roger-Pol Droit, do "Le Monde", e publicada com o título "A epopeia de um sentido". Disponível em: $<\mathrm{http}: / / \mathrm{www} 1$. folha.uol.com.br/fsp/mais/fs2902200407.htm>. Acesso em: 15 fev. 2018. 
ridade e dialética entre reconhecimento e desconhecimento, Ricoeur chama a atenção para uma das questões mais pertinentes da atualidade: produção de riqueza e desigualdade social. Em vez da riqueza gerar igualdade e justiça, o que se vê é o contrário, as diferenças acentuadas entre os que têm e os que não têm. A produção de desigualdade pelo dinheiro é a negação do reconhecimento. Desse modo, o indivíduo que, por um lado, é reconhecido juridicamente, por outro lado, não é reconhecido socialmente, sofrendo, conforme Ricoeur, de um desprezo fundamental.

O significado de reconhecimento em Ricoeur não está fechado nas possibilidades de definição do termo. É cada uma delas e mais do que elas. O reconhecimento se faz no percurso do desconhecimento originário marcado pela competição, desconfiança e individualidade para o estabelecimento de uma relação de mutualidade, confiança e coletividade "firmada pela característica de abundância do coração, ou seja, dar sem a preocupação de ser retribuído, do reconhecer não pelas categorias que 'eu' estabeleço, mas pelo que o outro se apresenta" ${ }^{17}$.

No tópico Multiculturalismo e "política de reconhecimento", do livro supracitado, Ricoeur pensa ser abusivo encerrar inteiramente o problema do reconhecimento na questão da discriminação das minorias oprimidas, ainda que esse seja hoje o aspecto mais popular do tema. Não se pode reduzir a discussão somente a essa questão, mas também não se pode ignorá-la de forma irresponsável. E mais do que isso, é preciso se engajar na luta pelo reconhecimento daqueles que foram subalternizados "admitindo a possibilidade de preservar, até mesmo reforçar, o caráter essencialmente 'dialogal' de uma reivindicação que assume uma dimensão francamente coletiva: é coletivamente, poder-se-ia dizer, que se exige um reconhecimento singularizante", afirma Ricoeur. ${ }^{18}$

$\mathrm{Na}$ nossa brevíssima explanação, em linhas gerais, sobre o reconhecimento em Hegel e Ricoeur, buscamos mostrar como o tema se inscreve de forma necessária na atualidade quando almeja dar voz e sentido às minorias. Tanto em Hegel como em Ricoeur, a relação de reciprocidade de reconhecimento das identidades está presente na dialética em que o "outro" está presente. Walter Mignolo faz um alerta a esse tipo de argumento quando diz que nos debates contemporâneos sobre alteridade, a categoria do "outro" corre o risco de ser uma invenção discursiva. Quem inventou o "outro" senão o "mesmo" no processo de construir-se a si mesmo? Tal exercício é resultado de um enunciado que não nomeia uma entidade existente, mas inventa. Segundo Mignolo:

O enunciado necessita um (agente) enunciador e uma instituição (não é qualquer um que pode inventar o anthropos); mas para impor o anthropos como "o outro" no imaginário coletivo é necessário estar em posição de gerenciar o discurso (verbal ou visual) pelo qual se nomeia e se descreve uma entidade (o anthropos ou "o outro"), e conseguir fazer crer que esta existe. Hoje a categoria de anthropos ("o outro") vulnera a vida de

${ }^{17}$ CORA, Élsio José; NASCIMENTO, Cláudio Reichert do. Reconhecimento em Paul Ricoeur: da identificação ao reconhecimento mútuo. In: Revista de Ciências Humanas, Florianópolis, v. 45, n. 2, p. 407-423, out. 2011. p. 422.

18 RICOEUR, Paul. Percurso do reconhecimento. São Paulo: Loyola, 2006. p. 228. 
homens e mulheres de cor, gays e lésbicas, gentes e línguas do mundo não-europeu e não-estadunidense desde a China até o Oriente Médio e desde a Bolívia até Gana ${ }^{19}$.

Na busca pelo reconhecimento, a consideração de Mignolo se faz pertinente. Não há reconhecimento quando não se é interpelado pela concretude da realidade do “outro". A teorização especulativa somente não é capaz de mobilizar a tarefa decolonial. Para uma decolonização de fato necessária se faz assumir a qualidade de vida dos subalternizados no reconhecimento da sua condição humana e lutar por sua libertação. O "outro" é real e concreto. Ele tem uma identidade definida: o índio, a mulher, o negro, os pobres, os gays e todas e todos que sofrem a marginalização social devido ao processo de hierarquização e exclusão. Portanto ver sua realidade com profundidade é fundamental para um reconhecimento devido.

\section{Provocações decoloniais à teologia cristã}

A teologia cristã é provocada a se decolonizar para criticar a matriz cultural do poder colonial ampliando então o seu horizonte epistemológico para ver e agir de modo eficiente junto aos movimentos sociais que vêm reivindicando antigos e novos direitos negados. As críticas feitas à modernidade/colonialidade abrem espaço para novos lugares de enunciação marcados pelo pensamento decolonial de sociedades que saíram de experiências de violência, servidão e dominação impostas pela colonização ocidental. A produção teórica decolonial possibilita outro olhar no campo teológico sensível às causas de grupos sociais marginalizados e silenciados. Não mais um olhar do senhor para o escravo, de cima para baixo, nem do escravo para o senhor, de baixo para cima, reproduzindo o processo da colonização, mas um "ver" difuso, humano, que reconhece as diferenças e dá a elas legitimidade.

O pensamento decolonial não pretende "simplesmente desarmar, desfazer ou reverter o colonial, passar de um momento colonial a um não-colonial”, mas provocar uma atitude transformadora (práxis) capaz de "transgredir, intervir, insurgir e incidir". O decolonial denota "um caminho de luta contínua no qual podemos identificar, visibilizar e incentivar 'lugares' de exterioridade e construções alternativas", afirma Catherine Walsh. ${ }^{20}$ Adotamos o termo "decolonial" para indicar que os objetivos dessa corrente vão além da superação do colonialismo ("descolonial”). A palavra remete a um sentido estratégico como um instrumento político, epistemológico e social

19 MIGNOLO, Walter. Geopolítica de la sensibilidad y del conocimiento: sobre descolonialidad, pensamiento fronterizo y desobediencia epistémica. In: CARBALLO, Francisco; ROBLES, Luis Alfonso Herrera (Eds.). Habitar la frontera: sentir y pensar la descolonialidad (Antología, 1999-2014). Barcelona: CIDOB; UACJ, 2015. p. 178.

20 WALSH, Catherine. Interculturalidad, Estado, Sociedad: Luchas (de)coloniales de nuestra época. Quito: Universidad Andina Simón Bolivar; Abya-Yala, 2009. p. 14-15. Disponível em: $<\mathrm{http}$ ://www.flacsoandes. edu.ec/interculturalidad/wp-content/uploads/2012/01/Interculturalidad-estado-y-sociedad.pdf $>$. Acesso em: 16 fev. 2018. 
de construção de instituições e relações sociais marcadas pela superação das lógicas opressoras que almejam uma geopolítica mundial perversa e desigual.

Para teóricos como Immanuel Wallerstein, Aníbal Quijano, Enrique Dussel e outros, a conhecida "modernidade", aparentemente positiva, esconde uma face oculta: a colonialidade. Sua lógica opera em domínios econômico, político, social e epistêmico, reforçando o controle da economia, na natureza e dos recursos naturais, do gênero e da sexualidade, da subjetividade e do conhecimento e, inclusive, o conhecimento teológico. A “colonialidade do poder", sugerida por Quijano, por exemplo, faz críticas ao pressuposto fundamental do paradigma europeu de conhecimento racional e sua aplicação nas relações de colonização. O conhecimento como produto da relação sujeito-objeto "nega a intersubjetividade e a totalidade como sedes de produção de todo conhecimento" 21 por causa do caráter falseador inerente ao sujeito, ser isolado da realidade, e ao objeto, "coisa" projetada pelo sujeito. Além disso, tal referência modelar "foi parte de uma estrutura de poder que implicava a dominação colonial europeia sobre o resto do mundo. Esse paradigma expressou, em um sentido demonstrável, a colonialidade dessa estrutura de poder" 22 .

A colonização do poder e seus desdobramentos sobre o ser (na subjetividade) e o saber (na epistemologia) não são provenientes somente da Europa, mas também dos Estados Unidos, do Norte Global ou de qualquer lugar que almeja estender seus tentáculos de dominação sobre minorias com o objetivo de estabelecer a hegemonia de uma única cultura e assim encobrindo o outro ${ }^{23}$ e marginalizando-o na periferia do sistema-mundo ${ }^{24}$. Tendo consciência dos processos de colonização, o próximo passo é a decolonização como tarefa capaz de "libertação social de todo poder organizado que alimenta a desigualdade, a discriminação, a exploração e a dominação"25. Essa tarefa se dá no "movimento de resistência teórico e prático, político e epistemológico, à lógica da modernidade/colonialidade"26, conhecido como "giro decolonial"27.

${ }^{21}$ QUIJANO, Aníbal. Colonialidad y modernidad-racionalidad. In: PALERMO, Zulma; QUINTERO, Pablo (Coord.). Aníbal Quijano: textos de fundación. Buenos Aires: Ediciones del Signo, 2016. p. 64.

${ }^{22}$ QUIJANO, 2016, p. 65.

${ }_{23}$ Fazemos referência aqui ao pensamento de Enrique Dussel, o qual afirma que o conceito da modernidade nasceu em 1492 como um momento concreto da origem de um "mito" de violência e encobrimento do não europeu. Cf. DUSSEL, Enrique. 1492: o encobrimento do outro: a origem do mito da modernidade. Petrópolis: Vozes, 1993.

${ }^{24}$ Conceito proposto por Fernand Braudel e desenvolvimento por Immanuel Wallerstein. Para Wallerstein, a partir do século XIX, praticamente todos os territórios do planeta haviam sido incorporados no sistema mundial capitalista. Heterogêneo em termos culturais, políticos e econômicos, o sistema mundial é constitutivamente dividido entre centro, periferia e semiperiferia, em função da divisão do trabalho entre as regiões. O centro é a área do desenvolvimento tecnológico; a periferia é o espaço marginal que fornece matérias-primas e força de trabalho; entre elas há uma região intermediária, a semiperiferia, que desempenha um papel de centro para a periferia e uma periferia para o centro. Cf. WALLERSTEIN, Immanuel. The Modern World System. New York: Academic, 1974.

${ }^{25}$ QUIJANO, Aníbal. La americanidad como concepto o América en el mundo moderno-colonial. In: PALERMO; QUINTERO (Coord.), 2016, p. 70.

${ }^{26}$ BALLESTRIN, Luciana. América Latina e o giro decolonial. Revista Brasileira de Ciência Política, Brasília, n. 11, maio/agosto de 2013. p. 105.

27 O termo "giro decolonial" foi desenvolvido pelo filósofo porto-riquenho Nelson Maldonado-Torres. 
Decolonial "significa pensar a partir da exterioridade e em posição epistêmica subalterna vis-à-vis à hegemonia epistêmica que cria, constrói, erige um exterior a fim de assegurar sua interioridade", diz Mignolo. ${ }^{28}$ Toda ação e reflexão de resistência às iniciativas hegemônicas e colonizadoras são tidas como contra-hegemônicas e decoloniais. A tarefa decolonial consiste em pensar a partir de outras línguas e categorias de pensamento que estão além dos pensamentos ocidentais dominadores. $\mathrm{O}$ exercício do "aprender a desaprender, e aprender a reaprender" 29 é constante nesse trabalho. Não se trata de negar todo conhecimento e todo progresso feito até o presente, mas rejeitar as imposições de dominação muitas vezes ocultas em tais empreendimentos.

\section{Novos lugares de enunciação teológica}

A enunciação corresponde ao momento de atualização da língua, o qual é atrelado a um conjunto de fatores e atos que provocam a produção de um enunciado. Esses "novos lugares", não reconhecidos pela política dominadora, são expressões de uma razão subalternizada que resiste ao pensamento que se impõe como único. O pensamento de fronteira ou "gnose liminar", como apresenta Mignolo, é uma reflexão crítica sobre a produção do conhecimento e implica sua redistribuição geopolítica até então pautada na colonização epistêmica e na subalternização de todas as formas de saberes, povos e culturas que não estivessem pautados nos cânones da ciência eurocêntrica. ${ }^{30}$

Pensar e fazer teologia a partir dos lugares fronteiriços significa aprender que existe o Sul, ir para o Sul, a partir do Sul e com o Sul. ${ }^{31}$ Essas são as orientações básicas para pensar e fazer teologia a partir das epistemologias do Sul Global, lugar subalternizado. O pensamento decolonial aponta para uma epistemologia alternativa ao pensamento hegemônico ocidental. "Epistemologias do sul" é o nome dado à percepção do mundo epistemologicamente diverso. $\mathrm{O}$ valor dado a essa alteridade tem o seu lugar não só na academia, como na relação entre o mundo científico e a pluralidade de saberes populares que são externos à ciência. A lógica da diversidade de epistemologias revela o domínio de produção de conhecimento, o regime cultural e civilizacional, de um sistema neoliberal global que estende seus tentáculos buscando o modo de ver e ser do sujeito no mundo. O "sul" agregado ao termo "epistemologias" é "concebido metaforicamente como um campo de desafios epistêmicos, que procuram reparar os danos e impactos historicamente causados pelo capitalismo na sua relação colonial com o mundo", afirma Boaventura de Sousa Santos. ${ }^{32}$

${ }^{28}$ MIGNOLO, Walter. Desobediência epistêmica: a opção descolonial e o significado de identidade em política. Cadernos de Letras da UFF - Dossiê: literatura, língua e identidade, n. 34, p. 287-324, 2008. p. 304.

${ }^{29}$ MIGNOLO, 2008, p. 305.

${ }^{30}$ MIGNOLO, Walter. Histórias locais/Projetos globais: colonialidade, saberes subalternos e pensamento liminar. Belo Horizonte: UFMG, 2003. p. 103.

31 SANTOS, Boaventura de Sousa; MENESES, Maria Paula (Orgs.). Epistemologias do sul. São Paulo: Cortez, 2010. p. 15.

32 SANTOS, 2010, p. 19. 
A necessidade de repensar ou recriar a teologia partindo da realidade opressiva do Sul Global passa a ser um desafio para uma intelecção da fé que acolhe a decolonialidade. $\mathrm{O}$ ser e o fazer, habitando as fronteiras, criam condições para ligar a epistemologia fronteiriça com a consciência dos empobrecidos, dos marginalizados ou dos subalternizados e, ao mesmo tempo, a desvinculação com um referencial teórico imperial e excludente. A teologia de fronteira não se empenha em se incluir como mais uma proposta teológica no rol das grandes teologias. Antes, sua meta é habitar a margem e se nutrir do diálogo entre os diferentes com o cuidado de não cair na imposição das ideologias.

A sensibilidade com as diferenças e o reconhecimento do outro são elementos constitutivos de uma teologia decolonial. Pesa sobre a teologia cristã a imagem de um saber imposto, autoritário, insensível com os diferentes. A relação com o pobre, muitas vezes, é vista de forma piedosa, no sentido paternalista, tratando-o como uma criança inocente. É evidente que a crítica do pensamento decolonial à teologia nem sempre se fundamenta, mas a provocação não deixa de ter sentido quando reconhecemos que, historicamente, a teologia se baseou na supressão tanto da sensibilidade como da localização geo-histórica do diferente. Por se julgar universal, exorcizou dos seus ambientes aqueles que não seguem o trâmite do que é tido como correto, verdadeiro, e assim reduziu o dessemelhante classificando-o como inferior.

A margem é espaço de oportunidades, de novas possibilidades e desafios. Para Homi Bhabha, as regiões marginais, fronteiriças são ideais para a construção de identidades porque favorecem a articulação de diferenças culturais num movimento de deslocamento e sobreposição de diferenças. Segundo ele, "esses 'entre-lugares' fornecem o terreno para a elaboração de estratégias de subjetivação - singular ou coletiva - que dão início a novos signos de identidade e postos inovadores de colaboração e contestação" 33. Esses espaços favorecem encontros entre povos, culturas e saberes que provocam a desinstalação do sujeito dos seus próprios ambientes. A teologia cristã que almeja ter o que dizer aos dilemas do mundo atual é interpelada a se desinstalar dos seus próprios ambientes e trilhar novos caminhos. Nesse nosso tempo, marcado por agudos problemas, sinais de esperança e profundas contradições, a busca por uma teologia consistente se intensifica e percorre caminhos múltiplos. Do espaço fronteiriço, novas narrativas emergem interpelando a fé cristã a proferir sua própria palavra de modo novo e libertador onde "os dialogantes encontram estratégias de interação/ negociação e de subversão, em que as identidades/centros são revistos, reconstruídos e criticados desde a margem" 34 .

${ }^{33}$ BHABHA, Homi. O local da cultura. 2. ed. Belo Horizonte: UFMG, 2013. p. 20.

${ }^{34}$ SOUZA, Daniel. Por trilhas e rumos ecumênicos: alguns caminhos para o diálogo inter-religioso. In: ; PEREIRA, Nancy Cardoso. Ecumenismo: um grão de salvação escondido nas coisas do mundo.

São Paulo: Fonte, 2014. p. 111. 


\section{O fazer teológico a partir do grito dos excluídos}

É preciso urgentemente ouvir o grito dos excluídos. Leonardo Boff, dez anos depois da publicação do livro Ecologia: grito da terra, grito dos pobres, continua alertando o mundo para que ouça "os muitos gritos dos oprimidos que clamam por libertação". O grito não é só do humano marginalizado, empobrecido, mas gritam as florestas, os rios, os solos, os ares, as espécies, enfim, "grita a Mãe Terra contra a qual está se levando uma guerra total: no solo, no subsolo, no ar, nos oceanos, em todas as frentes; guerras da qual não temos qualquer chance de ganhar, pois nós precisamos da

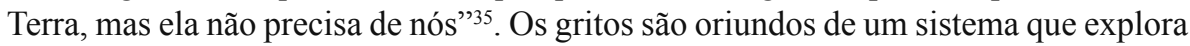
a vida em nome da riqueza e do poder de pouquíssimos.

A lógica que empobrece a maioria dos seres humanos é a mesma que depreda a Terra. A encíclica Laudato Si despertou a atenção do mundo quando denuncia as mazelas de um sistema econômico que, em nome do lucro, ignora a degradação ambiental e a humana. "Neste sistema que tende a fagocitar tudo para aumentar os benefícios, qualquer realidade que seja frágil, como o meio ambiente, fica indefesa face aos interesses do mercado divinizado, transformados em regra absoluta (56)"36. $\mathrm{O}$ papa Francisco faz frente à desumanização provocada pela idolatria do mercado e recorda de que "o planeta é de toda a humanidade e para toda a humanidade (190)" e, por isso, "é preciso alongar mais o olhar e abrir os ouvidos ao clamor dos outros povos (190)" para a prática do respeito e solidariedade. ${ }^{37}$

A teologia cristã atenta ao grito dos excluídos tem o dever de interpretar o momento atual com lucidez, conjugando a hermenêutica dos textos sagrados com a hermenêutica da vida expressa em um estilo de vida que testemunhe o seguimento de Jesus Cristo. Os novos lugares de enunciação da teologia são espaços capazes de correlacionar a verdade revelada com o humano enquanto sujeito interpretante. Para Claude Geffré, a "interpretação da significação atual do acontecimento Jesus Cristo a partir das diversas linguagens da fé suscitadas por ele, sem que nenhuma delas possa ser absolutizada, nem mesmo a do Novo Testamento" "38, é condição de possibilidade para outras compreensões e novas elocuções da fé. Uma teologia em perspectiva decolonial se abre a expressões de uma razão (saber) subalterna, que foi historicamente silenciada pela imposição de linguagens hegemônicas. "Portanto, a interpretação da bíblia não pode ser neutra; precisa deixar surgir o entendimento que só se descobre quando seu texto é lido em solidariedade com a comunidade dos pobres e oprimidos" 39 .

${ }^{35}$ BOFF, Leonardo. Ecologia: grito da terra, grito dos pobres: dignidade e direitos da Mãe Terra. Ed. rev. ampl. Rio de Janeiro: Vozes, 2015. p. 7-8.

${ }^{36}$ PAPA FRANCISCO. Carta Enciclica Laudato Si: sobre o cuidado da casa comum. São Paulo: Paulinas, 2015. p. 50.

${ }^{37}$ PAPA FRANCISCO, 2015, p. 157.

${ }^{38}$ GEFFRÉ, Claude. Como fazer teologia hoje: hermenêutica teológica. São Paulo: Paulinas, 1989. p.18.

39 FITZMYER, Joseph. A Bíblia na Igreja. São Paulo: Loyola, 1997. p. 62. 
Uma teologia que aspire ser decolonial precisa estar disposta a abrir mão das suas capas colonialistas. "As certezas teológicas prévias parecem cerrar o coração e o entendimento, para dar um valor absoluto aos sinais que permitem reconhecer a Jesus pelo que realmente é", afirma Segundo. ${ }^{40}$ Libertar a teologia das suas amarras coloniais significa desvincular à intelecção da fé de todo projeto de dominação em um esforço por manter a força libertadora da Boa-Nova de Jesus Cristo. Sua práxis é fruto de um compromisso histórico em que as consciências se transformam fazendo de homens e mulheres protagonistas de uma nova realidade. A teologia que daí emerge faz da vida concreta o lugar ideal para as formulações teóricas. Segundo Paulo Freire: "A reflexão só é verdadeira quando nos remete ao concreto sobre o qual a exercemos"41.

Teologia cristã comprometida com os processos de libertação precisa: primeiro, ser consciente do chão que pisa e do contexto em que está inserida; segundo, ter uma marca de inconclusividade diante nos dinamismos da vida, sempre aberta a se refazer e; terceiro, saber se posicionar com criatividade na tarefa de correlacionar a fé cristã e a situação existencial. Não basta ter consciência dos processos de colonização e não almejar mudanças concretas. As provocações decoloniais são legítimas quando impulsionam o fazer decolonial. A teologia do reconhecimento, sensível aos horizontes como possibilidade para o labor teológico, é capaz de se engajar efetivamente em projetos universais empenhados em assentar as bases para uma sociedade diferente.

“Não se trata de apostar em 'desenvolvimentos' alternativos, e sim construir alternativas ao desenvolvimento", afirma Miriam Lang. ${ }^{42}$ Projetos como os dos Direitos Humanos, dos Direitos da Natureza, do pós-extrativismo e outros, associados aos princípios regentes do Bem Viver e/ou da ética do Bem Comum, são esforços alternativos de construção por outro mundo possível. Por uma questão de delimitação, nos deteremos especificamente na ética do Bem Comum como horizonte de sentido capaz de balizar o fazer teológico.

\section{Em busca de uma ética do Bem Comum}

Na palestra de abertura do $31^{\circ}$ Congresso Internacional da Sociedade de Teologia e Ciências da Religião - Soter, com o tema "Religião, Ética e Política", Leonardo Boff disse que dois fatores atingiram o coração da ética: o processo de globalização e a mercantilização da ética. Para Boff, a globalização relativizou a ética ocidental fundando uma razão instrumental, enquanto a economia de mercado transformou tudo em mercadoria. Esses são os dois grandes empecilhos para uma ética mundial. Boff sugere uma "ética do cuidado" pautada em parâmetros mínimos de solidariedade,

${ }^{40}$ SEGUNDO, Juan Luis. Libertação da teologia. São Paulo: Loyola, 1978. p. 91.

${ }^{41}$ FREIRE, Paulo. Ação cultural para a liberdade. 5. ed. Rio de Janeiro: Paz e Terra, 1981. p. 88.

${ }^{42}$ LANG, Miriam. Alternativas ao desenvolvimento. In: DILGER, Gerhard; LANG, Miriam; FILHO, Jorge Pereira (Orgs.). Descolonizar o imaginário: debates sobre pós-extrativismo e alternativas ao desenvolvimento. São Paulo: Autonomia Literária; Elefante, 2016. p. 31. 
justiça e responsabilidade. ${ }^{43}$ Em outro momento, Boff já falava da urgência de um "ethos mundial" como o conjunto das inspirações, dos valores e dos princípios que orientarão as relações humanas para com a natureza, para com a sociedade, para com as alteridades, para consigo mesmo e para com o sentido transcendente da existência capaz de responder às crises social, do sistema de trabalho e a ecológica. Essa nova ética "nasce de uma nova ótica. E toda nova ótica irrompe a partir de um mergulho profundo na experiência do Ser, de uma nova percepção do todo ligado, religado em suas partes e conectado com a Fonte originária donde promanam todos os entes" ${ }^{\prime 44}$.

A racionalidade moderna deixou um vazio existencial no sujeito contemporâneo. Todo avanço tecnocientífico não foi capaz de preencher de sentido o humano e o seu universo. A perda da dimensão da sacralidade do mundo deu lugar ao niilismo, isto é, a negação da possibilidade de verdade, critica as certezas adquiridas e a perda gradativa da feição religiosa. "A maioria dos seres humanos vive atualmente num estado de desespero reprimido, tentando encontrar formas de distraírem-se das duras realidades do nosso tempo", constata Albert Nolan. ${ }^{45} \mathrm{O}$ impacto desse vazio sobre o comportamento dos seres humanos é inevitável. Instalou-se uma moralidade irresponsável nas relações sociais e ambientais de tal forma que não discernimos mais com clareza o certo do errado, o justo do injusto. O desequilíbrio atingiu o nosso próprio ethos - "nossa matriz de percepção, de avaliação e de ação não nos dá mais a base consensual de sustentação comum, enquanto uma evidência em si", diz Nilo Agostini. ${ }^{46}$

Contrariando a crença de que o mundo moderno seria secularizado, Peter Berger observa o ressurgimento da religião em termos globais. "O que quero destacar é que a pressuposição de que vivemos em um mundo globalizado é falsa. O mundo hoje [...] é furiosamente religioso como sempre foi e, em alguns lugares, mais do que nunca", afirma Berger. ${ }^{47}$ É o caso da América Latina, em que o efervescer religioso desafia os teóricos da religião mais preparados. A oposição de hoje não é tanto à religião, mas à sua institucionalização. O questionamento de hoje é sobre a legitimidade da tradição de fé que cristalizou o sagrado e fez do discurso da salvação um instrumento de domesticação evocando ideias de exclusivismo e de exclusão. ${ }^{48}$ Por isso a crescente busca por uma espiritualidade leiga livre de toda forma e fôrma em que "a experiência do divino está tomando o lugar das teorias sobre ele", afirma Harvey Cox na sua explanação sobre o futuro da fé no século XXI. ${ }^{49}$

${ }^{43}$ BOFF, Leonardo. Religião, ética e política no contexto atual. In: KUZMA, Cesar; CAPPELLI, Marcio (Orgs.). Religião, ética e política. São Paulo: Paulinas, 2018. p. 13-21.

${ }^{44}$ BOFF, Leonardo. Ethos mundial: um consenso mínimo entre os humanos. 2. ed. Rio de Janeiro: Sextante, 2003. p. 17.

${ }^{45}$ NOLAN, Albert. Jesus hoje: uma espiritualidade de liberdade radical. São Paulo: Paulinas, 2008. p. 28.

${ }^{46}$ AGOSTINI, Nilo. Ética cristã e desafios atuais. Rio de Janeiro: Vozes, 2002. p. 20.

47 BERGER, Peter L. The desecularization of the world: resurgent religion and world politics. Grand Rapids, Michigan: William B. Eerdmans, 1999. p. 2.

${ }^{48}$ Cf. CORBÍ, Marià. Para uma espiritualidade leiga: sem crenças, sem religiões, sem deuses. São Paulo: Paulus, 2010.

${ }^{49}$ COX, Harvey. O futuro da fé. São Paulo: Paulus, 2015. p. 35. 
O tema da ética inscreve-se nesse contexto com o objetivo de refletir sobre os problemas fundamentais da moral como: a finalidade e sentido da vida, os fundamentos da obrigação e do dever, a natureza do bem e do mal, o valor da consciência moral e outros. Sem entrar em maiores detalhes filológicos, a ética e a moral estão correlacionadas, mas são distintas. Todas as morais, por mais diversas, nascem de um transfundo comum, que é a ética. Enquanto esta remete à natureza humana, aquela aponta para distintas formas de expressão cultural. A ética preocupara-se "em elaborar uma reflexão sobre as razões de se desejar a justiça e a harmonia e sobre os meios de alcançá-las". Já a moral se envolve na "construção de um conjunto de prescrições destinadas a assegurar uma vida em comum justa e harmoniosa" ${ }^{50}$.

O ser humano é um ser social e toda conduta sua tem significado social. Envolve não simplesmente o modo como nos relacionamos com os outros, mas como os grupos se associam, a fim de agirem de modo responsável. Na contramão do individualismo, do consumismo e de toda forma de ismo que aliena e desumaniza, a ética do Bem Comum ressurge na atualidade como expressão necessária para a ética social. Nessa busca do bem comum de toda a sociedade, a partir do bem de cada um de seus membros, o pensamento social sublinha um conceito integral e inclusivo do bem. Esse bem está relacionado com todas as dimensões do humano e da criação. Com significados diversos e utilizada por várias áreas do conhecimento, a ética do Bem Comum remete à tradição da filosofia clássica grega e a sua apropriação pelo cristianismo. A Doutrina Social da Igreja formulou o seu conceito na encíclica Pacem in Terris (1963) no pontificado do papa João XXIII como: "O bem comum consiste no conjunto de todas as condições de vida social que favoreçam o desenvolvimento integral da personalidade humana e sua sociedade" 51 . Na atualidade, o papa Francisco retoma o tema do bem comum com citação de Pacem in Terris na carta encíclica Laudato Si: sobre o cuidado da casa comum, e exorta dizendo:

Toda a pretensão de cuidar e melhorar o mundo requer mudanças profundas "nos estilos de vida, nos modelos de produção e de consumo, nas estruturas consolidadas de poder, que hoje regem as sociedades". O progresso humano autêntico possui um caráter moral e pressupõe o pleno respeito pela pessoa humana, mas deve prestar atenção também ao mundo natural e "ter em conta a natureza de cada ser e as ligações mútuas entre todos, em um sistema ordenado" 52 .

O Bem Comum está relacionado com a dignidade humana. Estabelecer efetivamente essa relação no mundo capitalista de hoje tem sido um grande desafio. A tensão entre os "bens da comunidade" e a "comunidade de bens" tem provocado a ética e a moral social na busca por uma comunhão humana justa e solidária.

${ }^{50}$ JAPIASSÚ, Hilton; MARCONDES, Danilo. Dicionário básico de filosofia. 3. ed. rev. Rio de Janeiro: Jorge Zahar, 2001.

${ }^{51}$ Cf. O conteúdo da encíclica Pacem in Terris: Disponível em: <http://w2.vatican.va/content/john-xxiii/pt/ encyclicals/documents/hf_j-xxiii_enc_11041963_pacem.html>. Acesso em: 20 fev. 2018.

52 PAPA FRANCISCO, 2015, p. 6. 
Diante de um sistema-mundo intolerante e excludente, os princípios do Bem Comum levam-nos a cultivar relações de reciprocidade, respeito e valorização de todas as formas de vida. Encontrar alternativas frente ao desenvolvimento a qualquer preço do sistema neoliberal e construir relações solidárias são os desafios colocados para todos que acreditam na possibilidade de um mundo diferente. A filosofia de comportamento socioambiental do Bem Comum contesta o modelo ocidental hegemônico do "bem-estar" com um estilo de vida alternativo inclusivo e compromissado com os direitos humanos e os direitos da natureza.

\section{Considerações finais}

Os indicadores sociais e ambientais não são nada favoráveis. Estamos vivendo uma crise civilizatória provocada por um modelo predatório de "desenvolvimento" oriundo dos limites do capitalismo e por sua ideologia neoliberal. A cultura do bem-estar presente no atual sistema econômico é marcada pelo apelo egocêntrico e consumista de uma pequena parcela da população mundial em detrimento da maioria. Os empobrecidos e o planeta são os que mais sofrem com esse sistema injusto e exclusivista. É preciso reconhecê-los como sujeitos dotados de valores e de direitos.

O pensamento decolonial emerge nesse contexto como denúncia e interpela a modernidade a revelar a sua face oculta: a colonialidade. $\mathrm{O}$ empreendimento conhecido como "modernidade/colonialidade", além de expansionista, geograficamente falando, é, sobretudo, um projeto de colonização do poder. O descobrimento, ou melhor, o encobrimento do outro no Sul Global subjugou culturas silenciando suas vozes e marginalizando seus saberes. Decolonizar significa confrontar as instâncias hegemônicas, sejam as do poder, quanto as do ser e do saber por meio de um giro de libertação que possibilite outras epistemologias. A tarefa decolonial é subversiva; é dar voz e vez ao subalternizado, por isso grafamos modernidade/colonialidade/decolonialidade.

Teologia cristã, de tarefa pública e contextual, não se omite diante da crise contemporânea. Ela se abre ao diálogo com outros saberes na busca de mediação entre o elemento da fé e a situação da sociedade. Sem tal perspectiva não seria possível aceder ao texto social e discernir a situação de opressão/colonização que afetam o subalternizado, que é o interlocutor e o destinatário principal da teologia em perspectiva decolonial. Acolher as teorias sociais decoloniais e deixar a teologia ser provocada por elas possibilita dar à intelecção da fé novos horizontes de reflexão.

No contexto de provocação do pensamento decolonial sobre a teologia cristã, a ética do Bem Comum se coloca como balizadora de um estilo de vida alternativo. Portadora de um conceito aberto, plural e amplo, a ética do bem viver revela toda a sua relevância ao apresentar ao mundo os seus ideais de sustentabilidade, equidade e inclusão. Não se trata de uma receita, com normas fixas, a ser implementada no presente, nem de um retorno à pré-modernidade, mas de parâmetro capaz de fomentar ações de luta e resistência. Sua crítica é sistêmica e com uma proposta alternativa para um mundo pós-capitalista e pós-socialista. A viabilização prática do seu projeto é como uma utopia realizável e realmente possível. 


\section{Referências}

AGOSTINI, Nilo. Ética cristã e desafios atuais. Rio de Janeiro: Vozes, 2002.

BALLESTRIN, Luciana. América Latina e o giro decolonial. Revista Brasileira de Ciência Política, Brasília, n. 11, maio/agosto 2013.

BERGER, Peter L. The desecularization of the world: resurgent religion and world politics. Grand Rapids, Michigan: William B. Eerdmans, 1999.

BHABHA, Homi. O local da cultura. 2. ed. Belo Horizonte: UFMG, 2013.

BOFF, Leonardo. A intolerância no Brasil atual e no mundo. Disponível em: $<$ https://leonardoboff.wordpress.com/2015/01/22/a-intolerancia-no-brasil-atual-e-nomundo/>. Acesso em: 06 fev. 2018.

Ecologia: grito da terra, grito dos pobres: dignidade e direitos da Mãe Terra. Ed. rev. ampl. Rio de Janeiro: Vozes, 2015.

.Ethos mundial: um consenso mínimo entre os humanos. 2. ed. Rio de Janeiro: Sextante, 2003. Religião, ética e política no contexto atual. In: KUZMA, Cesar; CAPPELLI, Marcio.

(Orgs.). Religião, ética e política. São Paulo: Paulinas, 2018.

COMTE-SPONVILLE, André. Dicionário filosófico. São Paulo: Martins Fontes, 2003.

CORA, Élsio José; NASCIMENTO, Cláudio Reichert do. Reconhecimento em Paul Ricoeur: da identificação ao reconhecimento mútuo. In: Revista de Ciências Humanas, Florianópolis, v. 45, n. 2, p. 407-423, out. 2011.

CORBÍ, Marià. Para uma espiritualidade leiga: sem crenças, sem religiões, sem deuses. São Paulo: Paulus, 2010.

COX, Harvey. O futuro da fé. São Paulo: Paulus, 2015.

DUSSEL, Enrique. 1492: o encobrimento do outro: a origem do mito da modernidade. Petrópolis: Vozes, 1993.

ENCÍCLICA Pacem in Terris: Disponível em: <http://w2.vatican.va/content/john-xxiii/pt/ encyclicals/documents/hf_j-xxiii_enc_11041963_pacem.html>. Acesso em: 20 fev. 2018.

FITZMYER, Joseph. A Bíblia na Igreja. São Paulo: Loyola, 1997.

FREIRE, Paulo. Ação cultural para a liberdade. 5. ed. Rio de Janeiro: Paz e Terra, 1981.

GEFFRÉ, Claude. Como fazer teologia hoje: hermenêutica teológica. São Paulo: Paulinas, 1989.

HEGEL, Georg Wilhelm Friedrich. Fenomenologia do espírito. 9. ed. Petrópolis: Vozes; Bragança Paulista: Ed. Universitária São Francisco, 2014.

HÉRITIER, Françoise. O eu, o outro e a intolerância. In: BARRET-DUCROCQ (dir.). A intolerância: Foro Internacional sobre a Intolerância, Unesco, 27 de março de 1997, La Sorbonne, 28 de março de 1997. Rio de Janeiro: Bertrand Brasil, 2000.

JAPIASSÚ, Hilton; MARCONDES, Danilo. Dicionário básico de filosofia. 3. ed. rev. Rio de Janeiro: Jorge Zahar, 2001.

LANG, Miriam. Alternativas ao desenvolvimento. In: DILGER, Gerhard; LANG, Miriam; FILHO, Jorge Pereira (Orgs.). Descolonizar o imaginário: debates sobre pós-extrativismo e alternativas ao desenvolvimento. São Paulo: Autonomia Literária; Elefante, 2016.

MIGNOLO, Walter. Desobediência epistêmica: a opção descolonial e o significado de identidade em política. Cadernos de Letras da UFF - Dossiê: literatura, língua e identidade, n. 34, p. 287-324, 2008.

. Geopolítica de la sensibilidad y del conocimiento: sobre descolonialidad, pensamiento fronterizo y desobediencia epistémica. In: CARBALLO, Francisco; ROBLES, Luis Alfonso Herrera (Eds.). Habitar la frontera: sentir y pensar la descolonialidad (Antología, 1999-2014). Barcelona: CIDOB; UACJ, 2015. 
MIGNOLO, Walter. Histórias locais/Projetos globais: colonialidade, saberes subalternos e pensamento liminar. Belo Horizonte: UFMG, 2003.

NOLAN, Albert. Jesus hoje: uma espiritualidade de liberdade radical. São Paulo: Paulinas, 2008. PAPA FRANCISCO. Carta Encíclica Laudato Si: sobre o cuidado da casa comum. São Paulo: Paulinas, 2015.

QUIJANO, Aníbal. Colonialidad del poder y clasificación social. Disponível em: < http://biblioteca.clacso.edu.ar/clacso/se/20140506032333/eje1-7.pdf>. Acesso em: 06 fev. 2018.

Colonialidad y modernidad-racionalidad. In: PALERMO, Zulma; QUINTERO, Pablo

(Coord.). Aníbal Quijano: textos de fundación. Buenos Aires: Ediciones del Signo, 2016.

. La americanidad como concepto o América en el mundo moderno-colonial. In: PA-

LERMO, Zulma; QUINTERO, Pablo (Coord.). Aníbal Quijano: textos de fundación. Buenos Aires: Ediciones del Signo, 2016.

RICOEUR, Paul. Percurso do reconhecimento. São Paulo: Loyola, 2006.

SANTOS, Boaventura de Sousa. Os direitos humanos na zona de contacto entre globalizações rivais. Disponível em: <http://www.boaventuradesousasantos.pt/media/Direitos\%20humanos\%20 globaliza\%C3\%A7\%C3\%B5es\%20rivais_Cronos2007.pdf>. Acesso em: 07 fev. 2018. ; MENESES, Maria Paula (Orgs.). Epistemologias do sul. São Paulo: Cortez, 2010.

SEGUNDO, Juan Luis. Libertação da teologia. São Paulo: Loyola, 1978.

SOUZA, Daniel. Por trilhas e rumos ecumênicos: alguns caminhos para o diálogo inter-religioso. In: ___ PEREIRA, Nancy Cardoso. Ecumenismo: um grão de salvação escondido nas coisas do mundo. São Paulo: Fonte, 2014.

VAZ, Henrique C. de Lima. Senhor e Escravo: uma parábola da filosofia ocidental, p. 23. Disponível em: <faje.edu.br/periodicos/index.php/Sintese/article/download/2175/2468>. Acesso em: 08 fev. 2018.

WALLERSTEIN, Immanuel. The Modern World System. New York: Academic, 1974.

WALSH, Catherine. Interculturalidad, Estado, Sociedad: Luchas (de)coloniales de nuestra época. Quito: Universidad Andina Simón Bolivar; Abya-Yala, 2009. Disponível em: <http:// www.flacsoandes.edu.ec/interculturalidad/wp-content/uploads/2012/01/Interculturalidad-estado-y-sociedad.pdf>. Acesso em: 16 fev. 2018. 